\title{
Viabilidade de Fusarium graminearum em sementes de trigo durante o armazenamento*
}

\author{
Francisco Xavier de Barros Telles Neto ${ }^{1}$, Erlei Melo Reis ${ }^{2 * *}$, Ricardo Trezzi Casa ${ }^{3}$
}

${ }^{1}$ Engenheiro Agrônomo; ${ }^{2}$ Faculdade de Agronomia e Medicina Veterinária, Universidade de Passo Fundo, Passo Fundo, RS, CP 631, 99001-970, erleireis@tpo.com.br; ${ }^{3}$ Centro de Ciências Agroveterinárias, Universidade do Estado de Santa Catarina, CP 281, 88520-000, Lages, SC, a2rtc@cav.udesc.br

Autor para correspondência: Erlei Melo Reis

* Parte da dissertação de Mestrado do primeiro autor

*** Bolsista do CNPq

Data da chegada: 02/02/2006. Aceito para publicação em: 29/4/2007.

\section{RESUMO}

Telles Neto, F.X.B.; Reis, E.M.; Casa, R.T. Viabilidade de Fusarium graminearum em sementes de trigo durante o armazenamento. Summa Phytopathologica, v.33, n.4, p.414-415, 2007.

A intensidade da giberela em espigas de trigo tem aumentado em função da adoção generalizada do plantio direto, com conseqüente aumento da incidência do agente causal em sementes. Sementes de trigo da cultivar Fundacep 36, com 29,8\% de incidência natural de Fusarium graminearum, foram armazenadas em sacos de polipropileno trançado, em câmara climatizada, com temperatura entre 18 e $20^{\circ} \mathrm{C}$ e controle parcial de umidade relativa do ar, durante 12 meses. O objetivo foi quantificar a viabilidade do fungo em função do tempo de armazenamento. As análises foram procedidas a intervalo de dois meses, por um período de 14 meses. Em cada época de avaliação foram tomadas 400 sementes, as quais foram submetidas ao teste de sanidade feito em meio de cultura de $1 / 4$ batata-sacarose-ágar. As sementes foram incubadas durante sete dias, a temperatura de $25^{\circ} \mathrm{C} \pm$ $2{ }^{\circ} \mathrm{C}$ e fotoperíodo de 12 horas. O fungo não foi detectado após 12 meses de armazenamento. Considerando-se a redução da viabilidade em função do tempo de armazenamento, sugere-se que a análise de sanidade de sementes de trigo, em relação à presença de $F$. graminearum, deva ser feita pouco tempo antes da semeadura, a fim de decidir-se pela necessidade ou não do tratamento das sementes com fungicida específico para o controle do patógeno.

Palavras-chave adicionais: fonte de inóculo, Gibberella zeae, sobrevivência.

\section{ABSTRACT}

Telles Neto, F.X.B.; Reis, E.M.; Casa, R.T. Viability of Fusarium graminearum in stored wheat seeds. Summa Phytopathologica, v.33, n.4, p.414-415, 2007.

Wheat head blight disease intensity has increased under notill, management with the consequence of increasing the incidence of the causal agent of scab in seeds. Wheat seeds of Fundacep 36 cultivar with $29.8 \%$ natural incidence of Fusarium graminearum, were stored in braided polypropylene bags, in climatic chamber at temperature between 18 and $20^{\circ} \mathrm{C}$ and partial control of air relative humidity, for 12 months. The objective of this work was to quantify the fungus viability according to the storage time. Seed testing was performed every two months, during 14 months. In each assessment time 400 seeds were taken which were submitted to the test using as substratum the culture medium $1 / 4$ strength potato-sucrose-agar + streptomycin. Seeds were incubated during seven days at $25^{\circ} \mathrm{C} \pm 2{ }^{\circ} \mathrm{C}$ temperature and photoperiod of 12 hours. Taking into consideration the decrease of viability according to the storage time, it is suggested that the wheat seed health test to detect the presence of $F$. graminearum should be performed in a short period of time before seeding, to decide whether to treat or not the seeds with specific fungicide to control the pathogenic fungus.

Additional Keywords: inoculum source, Gibberella zeae, survival.

A giberela do trigo é uma doença de infecção floral tendo como agente causal o fungo Gibberella zeae (Schwabe) Petch. [forma assexuada Fusarium graminearum Schwabe]. A ocorrência e a intensidade da doença tem aumentado em função da adoção generalizada do plantio direto. Tal fato tem propiciado um aumento na incidência do fungo em sementes $(6 ; 2)$.

O fato das sementes permanecerem viáveis por longo período de tempo faz com que os microrganismos a elas associados também sobrevivam nesse período, dependendo apenas do hospedeiro, da natureza intrínseca do patógeno ou da sua localização na semente e das condições de armazenamento (5).

$\mathrm{O}$ fungo associado à semente pode ser transmitido à plântula causando podridões de raízes seminais, mesocótilos, raízes secundárias ou coronais, lesões em coleóptilo, coroas e morte de plântulas, logo após a emergência $(9 ; 7)$. A podridão comum de raízes (PCR) tem potencial para causar danos no rendimento de grãos de trigo de até $20 \%$ (3). Esses dados foram gerados antes da generalização do plantio direto e por isso, hoje, provavelmente, os danos podem ser superiores.

O objetivo do presente trabalho foi avaliar a viabilidade do $F$. graminearum em sementes de trigo armazenadas pela quantificação da incidência do fungo nas sementes em função do tempo de armazenamento.

O experimento foi conduzido nos Laboratórios de Sementes e de Fitopatologia da Faculdade de Agronomia e Medicina Veterinária 
da Universidade de Passo Fundo, no período de março de 2002 a março de 2003.

As sementes foram oriundas da safra de 2001, produzidas e colhidas em dezembro, no município de Vacaria, RS. No início de março de 2002, dois meses após a colheita, o experimento iniciou com o armazenamento de $10 \mathrm{~kg}$ de sementes, com $13 \%$ de umidade, em saco de polipropileno trançado, mantidas em câmara climatizada, com temperatura de 18 a $20^{\circ} \mathrm{C}$ e controle parcial de umidade relativa do ar $(35-40 \%)$ feita por desumidificadores. O experimento constou de sete avaliações feitas a intervalo de dois meses.

Para avaliar a viabilidade do fungo, utilizou-se meio de cultura $1 / 4$ BSA $(50 \mathrm{~g}$ de batata, $5 \mathrm{~g}$ de sacarose e $15 \mathrm{~g}$ de ágar para $1.000 \mathrm{ml}$ de água) acrescido de antibiótico (sulfato de estreptomicina $0,2 \mathrm{~g} \mathrm{em} 50$ $\mathrm{ml}$ de água esterilizada) após autoclavagem e quando a temperatura encontrava-se a, aproximadamente, $50^{\circ} \mathrm{C}$. Depois da assepsia das sementes em hipoclorito de sódio $(1 \%)$ por três minutos, seguida de lavagem com água esterilizada, 400 sementes (quatro repetições de 100 sementes) foram distribuídas em caixas plásticas tipo gerbox ( 25 sementes por caixa), medindo 11,5 x 11,4 x 3,4 cm de altura, contendo o meio de cultura. O material foi mantido em câmara de crescimento, num arranjo de tratamentos completamente ao acaso, sob temperatura de $25^{\circ} \mathrm{C} \pm 2{ }^{\circ} \mathrm{C}$ e fotoperíodo de 12 horas proporcionado por lâmpadas fluorescente, luz do dia, de $40 \mathrm{~W}$, distantes das caixas em $40 \mathrm{~cm}$. Após sete dias de incubação, identificou-se e quantificou-se a presença da colônia do fungo sob estereoscópica binocular (marca Zeiss, Stemi 2000-C, aumento de $40 \mathrm{x}$ ), com base em suas características morfológicas de acordo com a literatura (1). Os resultados foram expressa como incidência da infecção do fungo (\%). Foi procedida a análise de regressão entre a incidência e o tempo de armazenagem.

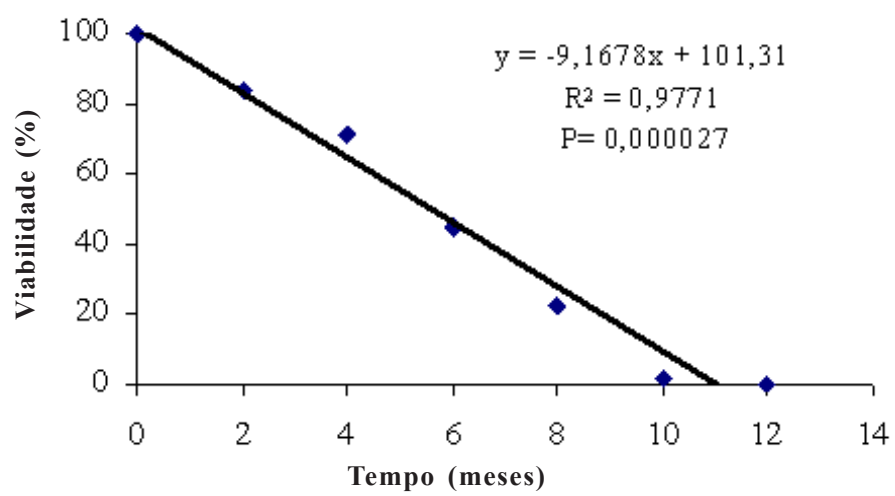

Figura 1. Viabilidade de Fusarium graminearum (y) em sementes de trigo em função do tempo (x) de armazenamento.

A incidência natural inicial de $F$. graminearum, em março de 2002, foi de $29,8 \%$, considerada como viabilidade de $100 \%$. Na representação gráfica da redução de viabilidade em função do tempo, os resultados mostraram que aos dez meses a incidência foi para $0,5 \%$ e chegou a zero aos 12 meses de armazenamento (Figura1). A relação entre a redução da viabilidade (y) em função do tempo $(\mathrm{x})$ gerou a seguinte função: $y=-9,1678 x+101,31 ; R^{2}=0,9771 ; P=0,000027$.

Fato semelhante foi relatado por Kabeere et al. (4), os quais verificaram que $F$. graminearum foi eliminado de sementes de milho, através da redução da umidade das sementes para 14\%, armazenando- as durante nove meses, com temperatura igual a $30^{\circ} \mathrm{C}$. Há carência de trabalhos relacionados à longevidade de $F$. graminearum em sementes de trigo, como também em outras culturas. Após um período de armazenamento de 22 meses, Reis et al. (8) não mais detectaram o fungo Pyricularia grisea Cooke (Sacc.) em dua cultivares de trigo. Observa-se que $F$. graminearum, no presente trabalho, perdeu a viabilidade num período menor do que $P$. grisea .

A colheita do trigo, no Rio Grande do Sul, realiza-se desde outubro até dezembro. As análises de sanidade das sementes, geralmente, são feitas depois de um a dois meses após a colheita. Por ocasião da semeadura na próxima safra, a incidência de $F$. graminearum, como também de outros patógenos, pode diminuir em função do armazenamento. Lembra-se que, em geral, em cultivos anuais, como o trigo, as sementes não são armazenadas por um período superior a sete meses. No presente trabalho, aos seis meses de armazenamento, quantificou-se a incidência de $12,5 \%$ do fungo nas sementes. Caso realizasse a semeadura com material com essa incidência, deveria ser, previamente, tratada quimicamente a fim de "zerar" a incidência o fungo para evitar a transmissão para órgãos radiculares e causar a podridão comum de raízes.

Com a equação gerada neste trabalho $(y=-9,1678+101,31)$ podese projetar o decréscimo linear da viabilidade do fungo em sementes. Considerando-se a incidência atual de uma semente em 100\%, cada mês de armazenagem determinou um decréscimo na viabilidade de $7,86 \%$ (Figura 1).

De acordo com os resultados, é fundamental avaliar a sanidade das sementes de trigo em relação à presença de $F$. graminearum, pouco tempo antes da semeadura, a fim de decidir-se pela necessidade ou não do tratamento das sementes com fungicida específico para o controle desse patógeno.

\section{REFERÊNCIAS BIBLIOGRÁFICAS}

1. Booth, C. The Genus Fusarium. Kew: Survey, C.M.I.. 1971. $238 \mathrm{p}$.

2. Casa, R.T.; Reis, E.M.; Blum, M.M.C.; Scheer, O.; Zanata, T.; Cardoso, C. Efeito do número de espiguetas gibereladas sobre o rendimento, o peso de mil grãos e a incidência de Fusarium graminearum em grãos de trigo. Summa Phytopathologica, Botucatu, v.30, p.277-280, 2004.

3. Diehl, J.A. Reação de cultivares de trigo à podridão comum das raízes. Pesquisa Agropecuária Brasileira, Brasília, v.17, n.12, p.1733-5, 1982

4. Kabeere, F.; Hill, M.J., Hampton, J.G. Effect of maize seed storage conditions on the survival of Fusarium spp. Seed Science \& Technology, Zurich, v.25, p.329-332, 1997.

5. Maude, R. B. Seedborne diseases and their control: Principles and practice. CAB INTERNATIONAL, Wallingford, 1996, 280 p.

6. Mauler-Machnik, A.; Zahn, K. Ear fusariosis in wheat - new findings on their epidemiology and control with Folicur. Pflanzenschutz-Nachrichten Bayer, Leverkusen, v.47. n.2, p.129$155,1994$.

7. Reis, E. M. Doenças do trigo $\mathbf{n}^{0}$ 1: podridão comum das raízes. São Paulo: 1988. 20p.

8. Reis, E.M.; Blum, M.M.C.; Forcelini, C.A. Sobrevivência de Pyricularia oryzae associado a sementes de trigo. Summa Phytopathologica, Jaguariúna, v.43, n.1, p.43-44, 1995.

9. Sutton, J. C. Epidemiology of wheat head blight and maize ear rot caused by Fusarium graminearum. Canadian Journal of Plant Pathology, Ottawa, v.4, n.2, p.195-209, 1982.(Footnotes) 